НЕЛЮБИН Павел Геннадьевич,

аспирант кафедры всеобщей истории и международных отношений Алтайского государственного университета (г. Барнаул).

Электронная почта: new-wirgil@yandex.ru

\title{
Западное образование в традиционной Японии: уроки иезуитов
}

\section{УДК 272/273 DOI https://doi.org/10.24866/2542-1611/2021-3/61-73}

В статье делается краткий обзор системы образования в Японии, действующей на момент прибытия туда первых христианских миссионеров-иезуитов. Выясняется, как местные учебные заведения повлияли на уровень грамотности японцев, а также на развитие науки и искусства. Анализируются мотивы, побудившие иезуитов основывать свои учебные заведения в Японии. Сравниваются две системы образования: действующая в Японии на момент прибытия туда иезуитов и альтернативная, созданная миссионерамииезуитами. Кроме того, рассматриваются особенности образовательной и воспитательной деятельности иезуитов в условиях японской культуры.

\section{Введение}

С момента своего основания в 1540 г., Общество Иисуса под руководством Игнасио де Лойолы (1491-1556 гг.), проявляло большой интерес к воспитанию молодежи. B IV части «Constitutiones» (1553 г.) И. Лайола подробно описал систему образования и основы, которые будут развиваться в различных типах учебных заведений, созданных иезуитами. Эти основы начали воплощаться в жизнь примерно полвека спустя, после окончательного одобрения официального плана по образованию иезуитов - «Ratio atque Institutio Studiorum Societatis Iesu» или сокр. "Ratio Studiorum» (1599 г.), в первую очередь предназначавшегося для Европы, но все же подходящего и для других регионов, в которых действовали миссионеры. С культурами, языками и религиями неевропейских народов, иезуиты, только приступившие к своему служению, были знакомы слабо. Тем не менее для успешного распространения христианства, в том числе посредством образования, необходимо было адаптироваться к существующим условиям. При этом важно было сохранить приверженность принципам св. Игнасио, отраженным в «Ratio Studiorum».

Христианская миссия в Японии была основана братьями-иезуитами из Общества Иисуса в середине XVI в. Данное событие примечательно тем, что с момента создания ордена иезуитов прошло всего лишь десять лет. Разумно предположить, что иезуиты с самого начала своей миссионерской деятельности в Японии проявляли большой интерес к изучению существующей в ней системы образования, к преподаваемым предметам и, соответственно, к созданию христианских учебных заведений в качестве важнейших помощников в христианизации. христианство в Японии, иезуиты, Общество Иисуса, педагогика иезуитов, миссионеры в Японии, образование в традищионной Японии
Для иитирования:

Нелюбин П. Г. Западное образование в традиционной Японии: уроки иезуитов // Известия Восточного института. 2021. № 3. C. 61-73. DOI https://doi. org/10.24866/2542-1611/2021 3/61-73 
Предметом нашего исследования являются особенности образовательной деятельности иезуитов в условиях японской культуры во времена «Христианского века» (1549-1650 гг.). Целью является выявление особенностей образовательной деятельности иезуитов в условиях японской культуры, а также сравнение двух систем образования: действующей в Японии на момент прибытия туда иезуитов и альтернативной, созданной миссионерами-иезуитами. Источниками для написания данной работы послужили письма и книги, написанные иезуитами и посвященные образованию в Японии рассматриваемого периода [4; 17]. Кроме того, были использованы исследования японских и западных ученых, на которых мы остановимся более подробно.

Отечественные исследователи при изучении системы образования в традиционной Японии касались влияния Запада, но специальных работ по системе образования иезуитов в Японии, организации учебных заведений и их особенностей, а также устройстве обучения и воспитательной системы на сегодняшний день нет.

Среди современных отечественных исследователей некоторые аспекты системы образования иезуитов в Японии были затронуты в работе О.В. Новаковой, Е.К. Симоновой-Гудзенко и М.Ю. Ульянова [1, с. 11]. Тут мы можем найти сведения о первых контактах европейцев со странами Восточной Азии в начальный период Новой истории, их роль в распространении европейских знаний о новых научных открытиях и новой для региона религии - христианстве. В части работы, посвященной Японии, мы можем проследить историю развития обмена научными знаниями между японцами и иезуитами (особенно в области географии и картографии).

Изучению образовательной системы иезуитов в традиционной Японии немало внимания уделили западные исследователи. Д. Моррис [8, р. 312] показывает трудности, с которыми столкнулись иезуиты при обучении местных жителей основам христианской веры и латыни. Следует обратить внимание на работу С. Огава [10], в которой достаточно подробно описывается история христианской живописи в Японии, а также особенности художественного образования в учебных заведениях иезуитов. В своем исследовании Д. Ранери [11, p. 201] приводит некоторые сведения о Художественной семинарии Джованни Никколо и перечисляет вероучительные тексты, включенные в учебные программы иезуитов.

Важную работу по изучению западного образования в традиционной Японии играют исследования японских ученых. В своей работе Т. Итиро [13, pp. 566-586] рассматривает историю европейского языкового образования в Японии, делая особый акцент на опыте иезуитов в обучении японцев латыни. С. Обара $[9$, р. 53] показывает вклад Франциска Ксавье (1506-1552 гг.) в развитие гуманитарного образования во время «Христианского века», попутно затрагивая историю основания учебных заведений иезуитов и их структуру.

\section{Образование в традиционной Японии}

Говоря об образовании, которое создавали и развивали иезуиты в традиционной Японии, в первую очередь необходимо остановиться на местной системе обучения. Когда первые христианские миссионеры прибыли в Японию, там уже существовали разнообразные учебные заведения, которые обеспечивали как базовое, так и профессио- 
нальное образование.

Самими распространенными и доступными были школы тэракоя 寺子屋, которые обычно создавались при буддийском храме. Монахнаставник, ответственный за храм, набирал мальчиков и учил их читать и писать. Как правило, обучение велось в отдельной комнате или корпусе (если таковой имелся). Возрастной контингент учеников был от шести до четырнадцати лет, за редкими исключениями. Чаще всего, монах лично обучал только самых продвинутых учеников, которые в свою очередь обучали других. Тэракоя является ярким примером функционирования системы сэмпай-кохай 先輩 後輩, когда более продвинутые и опытные ученики сэмпай, обучают младших ко-

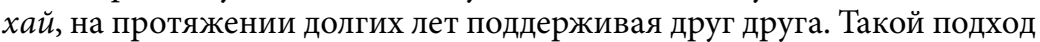
способствовал развитию сплоченности японского общества. Основы буддизма преподавались посредством обучения чтению и письму, так как тексты, при помощи которых дети учились читать, изначально носили религиозный характер или были пронизаны буддийскими и конфуцианскими идеями. К примеру, одним из популярных текстов в обучении был «Тэйкинорай» 庭訓往来 $(\approx 1320$ г.) [16, с. 17]. Точное время появления тэракоя неизвестно, однако, по общему мнению, первые школы такого типа появились еще в Период Хэйан (7841185 гг.). К середине XVI в. теракоя находились в большом упадке, впрочем, как и вся страна в Период Сэнгоку (вторая половина XV начало XVII вв.). В первые годы правления сёгуната Токугава ситуация заметно улучшилась, тэракоя процветали как никогда прежде. Так, к середине XVI в. около 20\% населения могли читать и писать в том числе благодаря этим учебным заведениям. Эти показатели даже выше тех, которые были в большинстве европейских стран того же периода $[14$, p. 50$]$.

Несмотря на то, что в японской литературе XV и XVI вв. часто встречаются произведения, высмеивающие глупость и неграмотность буддийских монахов, нет сомнений, что именно благодаря им на тот момент в стране был высокий уровень грамотности, впечатливший христианских миссионеров.

После окончания тэракоя, выпускники, научившиеся читать и писать, но не желавшие становится монахами, часто поступали в учебные заведения более высокого уровня - universidades ${ }^{1}$. Образовательный процесс в них базировался на двух предметах: 1) кункогаку 訓詁学 (экзегетика классических китайских текстов), 2) бунсо: 文藻 (литература). Во времена большей интеллектуальной активности студенты могли изучать китайские философские трактаты (особенно конфуцианские) и буддийские сутры. Однако, в худшие времена образование могло ограничиться изучением зачатков классической японской поэзии и китайской истории. Наибольшую известность получила Асикага Гакко (足利学校) - старейшее академическое учебное заведение в Японии. Там, помимо традиционных дисциплин, преподавалась китайская медицина.

Обратим внимание на основные отличия японских universidades от европейских университетов. Первое отличие заключается в том, что в японских «университетах» воспитание характера и развитие положительных черт личности учеников ценилось гораздо выше, чем интеллектуальное образование, в то время как в Европе нравственным образованием занимались школы, но не университеты (за исключением
1 Такое название им дали миссионеры-иезуиты. В японском языке достаточно сложно подобрать термин, объединяющий эти учебные заведения и подчеркивающий их статус. Важно заметить, что японские universidades не имели практически ничего общего с европейскими университетами. 
духовных). Вторым отличием можно считать особенность передачи знаний от преподавателя к учащимся. В европейских университетах, обсуждение новой информации в рамках дискуссии между преподавателем и учащимися считалось нормальной практикой, тогда как в Японии слова преподавателя не должны были обсуждаться и подвергаться сомнению. Отсюда вытекает еще одно отличие - центральное место текста в японских universidades. В Европе же куда больше ценилась устная лекция. Кроме того, в европейских университетах стремились к тому, чтобы дать как можно больше различной информации. В Японии намеренно ограничивали количество предметов, чтобы дать более глубокие знания в определенных областях.

Важнейшей частью японской системы образования были «семейные школы» иэмото 家元 (досл. «основа семьи»). Человек, желавший стать каллиграфом, врачом, художником, мастером чайной церемонии, актером и т.д., должен был закончить такую школу. Важной чертой этих школ являлось то, что должность главы школы - мастера (учителя), являлась наследственной. Причем знания, передаваемые наследнику, были секретными и считались более глубокими. Но все же были редкие исключения, когда наиболее талантливый ученик, не имевший кровного родства с мастером, при условии усыновления избирался преемником.

Практически в обязательном порядке учениками становились дети главы школы. Кроме того, в иэмото принимали не только членов семьи, но и других людей - по рекомендации. Традиционно, в большинстве случаев, ученики в иэмото относились к мастеру как к отцу, отдавая ему почести, приписываемые родителям. Крайне редко в иэмото велись лекции, обычно все знания приобретались на практике. Когда навыки ученика признавались мастером, он получал свидетельство и имел право покинуть школу, чтобы самостоятельно заниматься своим ремеслом от имени школы, становясь мастером определенной семейной традиции. Система наследственности «от отца к сыну» обеспечивала сохранение монополии на совокупность определенных знаний внутри семьи.

Домашний вид обучения так же был весьма распространен в традиционной Японии, в первую очередь среди детей знати. Хотя некоторые дети самураев посещали тэракоя, большинство из них обучалось чтению и письму, а также классическим и боевым искусствам дома. Для девочек же нанимали наставников, которые обучали их главным образом «женской азбуке» и правилам этикета.

\section{Образование иезуитов}

Учитывая вышеперечисленные факты о «местном» образовании в традиционной Японии, стоит заметить, что они не могли не повлиять на образовательную деятельность иезуитов. Хотя в первое время под руководством Франциска Кабрала (1529-1609 гг.), который не верил в способность японцев думать и обучаться, иезуиты практически не развивали образование в Японии. Ф. Кабрал был убежден, что у японских новообращенных не было достаточной образованности, чтобы быть допущенным к Обществу Иисуса, и что эти «надменные, жадные, ненадежные и неискренние» лица могут находиться максимум в статусе помощников в домашнем хозяйстве [13, р. 570]. Политика миссии изменилось с назначением на должность визитора Алессан- 
дро Валиньяно (1539-1606 гг.), который считал, что европейские миссионеры должны изучать японский язык, чтобы завоевать сердца и умы местных жителей, и должны изменить свои привычки, чтобы погрузиться в японские обычаи. Политика А. Валиньяно по адаптации к японской культуре в то время была довольно новаторской и даже революционной. Так, непримиримая позиция Ф. Кабрала и явное нежелание идти на компромисс, представляли собой норму среди европейских миссионеров в Азии в XVI в. А. Валиньяно видел необходимость в том, чтобы священнослужители-японцы вовлекались в миссионерскую службу, так как полагал, что в долгосрочной перспективе будет эффективнее, если сами японцы будут распространять христианство в своей стране. Именно по его инициативе иезуиты начали обучать мальчиков из высоких сословий, многие из которых в последствии присоединились к Обществу Иисуса.

Но не только А. Валиньяно продвигал подобные идеи. В одном из своих писем $Ф$. Ксавье описывает некоторые достоинства японцев:

«На острове Иапо, который находится за пределами Китая, на расстоянии двенадцать сотен лиг или более, живут люди, которые испытывают огромное любопытство в вопросах, связанных с Богом и науками и очень радуются, когда узнают что-то новое...» [4, с. 791];

«...и мне кажется, что среди неверующих людей, нет таких, которые могут превзойти японцев. Они очень грамотно общаются, и вообще добрые, без злых намерений» [4, с. 791];

«Многие люди умеют читать и писать, что создает хорошую среду для изучения молитв и дел Божьих» [4, с. 791].

Что примечательно, иезуиты, хоть и немногословно, но признавали заслуги японских учителей: «в этих монастырях монахи держат много кошек, а еще там есть дети идальго, которых они учат читать и писать» $[4$, с. 791$]$.

Хотя можно найти свидетельства миссионеров, в которых личные качества японцев описываются не с самой лучшей стороны (им приписывались горделивость, скрытность и слабый интеллект), всё же в большинстве писем мы видим противоположную точку зрения. Японцев хвалят за честность, бережливость, трудолюбие, здоровое любопытство и хорошие манеры в общении. Вполне справедливо, что $Ф$. Ксавье, как и его братья по вере, говорили о том, что японцы готовы к принятию христианства, что они нуждаются в нем. По мнению $Ф$. Ксавье, христианское учение в Японии, необходимо было распространять опираясь на твердые философские и богословские знания. Он хорошо понимал, что предстоят горячие споры с местным духовенством. Так, в своем письме он дает наставления будущим миссионерам:

«Те, кто прибудет сюда, должны иметь знания, чтобы отвечать на вопросы, порой очень сложные и делать это с утра до ночи... Каков Бог и где он находится, почему его не видят, почему у душ есть начало и нет конца, и другие очень сложные вопросы» [4, с. 791].

Безусловно, для того, чтобы отвечать на подобные вопросы (или задавать их) необходимо было владеть японским языком на достаточно хорошем уровне. Кроме того, язык был необходим для уверенной аргументации своей позиции в спорах с буддийскими монахами и конфуцианскими учеными. Так появилась необходимость в создании учебных заведений, где иезуиты могли изучать японский язык и мест- 
ную культуру. Если опираться на письмо Ф. Ксавье от 1549 г., можно утверждать, что планы о создании учебных заведений для миссионеров на территории Японии были уже тогда. Однако ввиду ряда факторов, в числе которых нехватка материальных и людских ресурсов, а также военные действия в разных уголках страны, этот план притворился в жизнь лишь спустя 30 лет. Тем не менее базовое (начальное) образование иезуиты начали развивать гораздо раньше.

Распространение христианства происходило весьма интенсивно, обращенные в новую веру японцы приводили в церковь своих детей. У иезуитов возникла естественная конкуренция с местным буддийским духовенством, за которым традиционно сохранялась сфера начального образования. Миссионеры скоро нашли "христианскую» альтернативу тэракоя - escola (порт. школа). Упоминания о первой escola относятся еще к 1561 г., и, по некоторым данным, в 1581 г. их количество возросло до 200 с наибольшей концентрацией на о. Кюсю $[19$, c. 30]. Обычно такие школы существовали при церквях. Если в населенном пункте не было церкви, но была крупная христианская община, жители так же организовывали escola. Как правило, учителями были новообращенные японские христиане, которые учили детей нормам этикета, чтению и письму на японском языке, арифметике, а также католическому катехизису. В крупных городах, помимо вышеперечисленного, могли преподавать португальский язык, латынь, музыку и изобразительное искусство.

Прибыв в Японию, А. Валиньяно среди прочих проблем отмечал отсутствие учреждений среднего и высшего образования, подчиненных миссионерам. Он созвал Консультацию в 1580 - 1581 гг., на которой среди прочих были подняты два вопроса, касающиеся образования: 1. Следует ли создавать seminario для японцев? 2. Есть ли необходимость в создании учебных заведений, в которых мы будем жить вместе, по типу colegio?

По итогам данной Консультации, было решено создать три типа учебных заведений.

В первую очередь выделим seminario. На территории Японии было две seminario и их местоположение часто менялось. Первая была основана весной 1580 г. в Арима, а вторая в мае того же года в Миако.

Фактически они являлись средними школами (интернат), главным образом предназначенными для обучения сыновей христиан-самураев и европейцев. Помимо христианского богословия, мальчиков обучали чтению и письму на японском языке и латыни, а также основам «европейских» наук (в первую очередь гуманитарных). Латыни здесь уделялось особое внимание, так как кроме статуса официального языка Католической церкви она была главным академическим языком, принятым в Европе. Миссионеры быстро поняли, что латынь, как и прочие европейские языки, сильно отличается от японского и поэтому отмечали важность изучения латыни японскими христианами с самого детства. Латынь изучалась в течении пяти с половиной часов каждый будний день, а также по утрам в субботу. При этом на пути освоения латыни существовал ряд сложностей. Во-первых, существовала серьезная нехватка преподавателей, в достаточной мере знающих как латынь, так и японский язык. Во-вторых, ощущалась острая нехватка учебной литературы и учащиеся были вынуждены переписывать учебники своих преподавателей [13, p. 570]. 
В качестве учебных материалов использовались отобранные тексты из классических произведений японской и европейской литературы. Иезуиты стремились достичь условий, при которых ученики смогут понять культурные особенности как европейской, так и японской культур. Важное место в программе обучения было отведено изучению местных религий. Буддийские монахи не могли не обращать внимание на христиан и пытались помешать их миссионерской работе, прежде чем она могла пустить корни в Японии. Христианские миссионеры и буддийские монахи часто вели открытые споры друг с другом. В seminario существовала необходимость в изучении японских религий и буддизма, чтобы учащиеся и выпускники чувствовали себя уверенно в теологических диспутах с монахами [17, с. 192]. Кроме того, студенты изучали музыкальное искусство, учились играть на органе. Орган, впервые доставленный в Японию в 1579 г. [15, с. 116], произвел большое впечатление на японцев, которые сочли его звучание привлекательным. Так, орган стал важным помощником иезуитов в обучении и миссионерской службе.

Несмотря на все сложности, seminario продолжали функционировать вплоть до 1614 г., пока не вышел «Указ о депортации священников» (伴天連追放之文).

Отдельно следует выделить Seminario dei Pittori (яп. セミナリヨの 画学舎). Её основал А. Валиньяно в 1583 г., а итальянец Джованни Никколо (1560-1626 гг.) стал её первым директором. Она была важным учебным заведением, а также производственным цехом, и впоследствии стала крупнейшей из созданных в Азии школой миссионерского искусства. Дж. Никколо познакомил японских художников не только с масляной живописью, но и с другими техниками и стилями, значительно отличающихся от японских.

Её создание мотивированно уникальной философией иезуитов, согласно которой рисование может способствовать духовному обогащению местных жителей. Считалось, что, если человек будет рисовать собственными руками, это сильно укрепит его внутреннюю веру. Так, миссионеры полагали, что местные (японские) художники, рисующие религиозные образы, будут способны создавать изображения, подходящие для духовных потребностей японцев. Кроме того, обучение созданию религиозных образов считалось эффективным методом, облегчающим катехизацию [6, p. 131].

Преподавателям и учащимся Seminario dei Pittori под гнетом гонений пришлось несколько раз переезжать в разные населенные пункты Японии, и в конечном итоге правительство распорядилось закрыть школу в 1614 г. Нескольким учащимся удалось сбежать в Макао, где они внесли свой вклад в создание церкви Святого Павла, а другие были отправлены в Китай.

Затем идут noviciado. Это религиозное учебное заведение, предназначенное для обучения правилам и принципам Общества Иисуса будущих иезуитов. Единственным учебным заведением подобного рода был Новициат Усуки, созданный в декабре 1580 г. А. Валиньяно настолько высоко ценил роль noviciado, что в первые два месяца существования Новициата Усуки лично давал уроки будущим иезуитам $[18$, c. 32].

Третьим типом учебных заведений были collegios, дающие высшее образование. Как и в seminario, молодые люди не только учились, но 
Табл. 1. Виды образовательных организаций иезуитов в традиционной Японии. Источник: составлено автором и жили там. Иезуиты стремились воспитать будущих религиозных и светских лидеров, способных управлять церквями и общинами, а также распространять христианство на всей территории Японии, и collegios предназначались для обучения таких людей. Содержание учебных программ, в соответствии с «Ratio Studiorum», было схожим с другими иезуитскими коллегиумами в Европе, но были и оригинальные курсы, учитывающие японскую специфику миссии (японский язык, религиозная культура Японии и т.д.). Единственное учебное заведение такого рода - Колледж Святого Павла, было основано в октябре 1580 г. в Фунаи (совр. Оита).

\section{Особенности педагогики иезуитов в Японии}

Итак, переходя к рассмотрению особенностей педагогики иезуитов, покажем систему образовательных учреждений миссионеров в традиционной Японии на таблице (табл. 1).

Хотя Миссия испытывала острую нехватку в педагогах и учебной литературе, иезуиты старались найти выход из этой ситуации. К примеру, seminario могла вместить примерно сто студентов, а поэтому очевидно, что для достижения большего прогресса были необходимы печатные учебники [10, p. 74]. Настоящим прорывом стал импорт европейского печатного станка в 1590 г. Если раньше иезуитам приходилось переписывать учебники, религиозную и классическую литературу вручную, теперь в этом не было необходимости. Кроме того, печатный станок использовали в Художественной семинарии для производства медных гравюр с изображением христианских святых.

Следует заметить, что для иезуитов, служащих в Азии, печать религиозных и педагогических текстов на месте была стандартной практикой. К примеру, в 1577 г. иезуит Энрике Энрикес (1520-1600гг.), использовал ручной печатный станок для распечатки и последующего распространения католического катехизиса на тамильском языке в Гоа. Однако, в отличие от латинского алфавита, который состоит из относительно небольшого для европейцев набора букв, японский язык казался непостижимым из-за большого количества новых незнакомых символов. Разумно предположить, что иезуиты пребывали в ожидании столкновения с некоторыми трудностями, которые могли возникнуть при печати текстов на японском языке. Первым миссионером, попытавшимся преодолеть эту проблему был А. Валиньяно. Первоначально А. Валиньяно планировал использовать в обучении только тексты, напечатанные на латинице. Он отправил японскую делегацию в Европу (Посольство Тэнсё, 1582-1590 гг.) и попросил послов изучить методы печати, актуальные для того времени, а так-

\begin{tabular}{|l|l|}
\hline \multicolumn{1}{|c|}{ Виды учебных заведений } & \multicolumn{1}{c|}{ Уровни образования } \\
\hline Collegio コレジオ & Высшее \\
\hline Noviciado ノビチアート & Новициат \\
\hline Seminario dei Pittori セミナリヨの画学舎 & Среднее (+дополнительное) \\
\hline Seminario セミナリオ & Среднее \\
\hline Escola 教会学校 & Начальное \\
\hline
\end{tabular}


же приобрести печатный станок [7, p. 312]. Успехи посолов были настолько впечатляющими, что превзошли предварительные ожидания А. Валиньяно - в дополнение к печатному станку, им удалось приобрели металлические штампы для печати иероглифов, а также символов японской слоговой азбуки кана. Посольство вернулось в Японию в 1590 г. Иезуиты разместили печатный станок в Кадзуса, на полуострове Симабара, и в том же году началась активная печать религиозной и образовательной литературы миссионеров.

Важной особенностью иезуитской педагогики, применявшейся во всех учебных заведениях (в том числе и в Японии), были: классноурочная система обучения, регулярные повторения пройденного материала и периодические конкурсы среди учащихся. Иезуитами была отработана методика лекций, построенная на устной последовательности изложения материала в несколько приёмов: 1) полное изложение; 2) анализ содержания лекций по частям; 3) дополнение историческими и др. справками; 4) стилистический анализ первоисточников.

Такой подход привел к впечатляющему результату. Так, Луиш Фройш отмечал, что удивлен скоростью, с которой японские студенты усваивают латынь, сказав, что его ученики всего за три-четыре месяца выучили то, на что европейский студент тратит три года [17. c. 192]. А. Валиньяно писал о том, что японские дети очень хорошо восприняли западное образование и учатся читать и писать на европейских языках даже быстрее, чем дети из Европы [17. с. 192]. Хотя такие сообщения звучат как преувеличение, можно предположить, что детям, изучающим японский язык, изобилующий иероглифами с множеством значений, было легче запоминать латинский или португальский алфавит, а затем целые слова.

Учитывая серьезную нехватку литературы и педагогов, а также особую общественно-политическую ситуацию в Японии, иезуиты корректировали учебные планы, фактически сокращая срок обучения. В качестве примера, приведем особенности учебного плана в collegio.

План разрабатывался с учетом потребностей Католической церкви в Японии. К примеру, изучение греческого языка для неяпонских студентов было заменено изучением японского языка и религиозной культуры Японии с опорой на классическую японскую литературу и буддийские религиозные тексты [3, с. 138].

Спустя 2-3 года изучения языков и европейских наук в collegio, студенты переходили к изучению философии и теологии. Содержание этих курсов хорошо показано в «Compendium catholicae veritatis» (講義 要綱) (или просто «Compendium»), представленного как в латинском, так и в японском варианте. Этот труд иезуита Педро Гомеса (1533-1600 гг.), составленный на основе трех работ - «De Sphaera», «De Anima», «De Fide», использовался не только для обучения в Колледже Святого Павла, но и в Колледже Святого Павла в Макао, куда в 1614 г. были вынужденно перенаправлены студенты из Японии [14, p. 50].

«De Sphera» содержала важные знания о космологии, метеорологии и теории материи, которые были достигнуты в конце XVI в. в Европе. Благодаря этой работе, мы можем увидеть, как иезуиты, стремящиеся избегать острых вопросов во время обучения для совершенствования межкультурных коммуникаций, в некоторых случаях твердо стояли на своем. 
К примеру, японцев шокировала теория о том, что Земля шарообразна, ведь они были уверены, что она плоская. Иезуиты не стали приспосабливаться к этой прочно-закрепившейся теории, принятой в Японии и продолжали настаивать на своем.

Трактат «De anima» опирается на одноименную работу Аристотеля. В нем содержатся представления о индивидуальности человеческой души, разуме и свободной воле. Он пытался прояснить, что, в отличие от животных, каждый человек наделен душой, и, благодаря этому, превосходит других существ. Эта точка зрения вступает в противоречие с традиционными японскими пантеистическими представлениями, не выделяющем людей среди прочих живых существ.

Работа «De Fide», во многом повторяющая «Catechismus Romanus» (1566 г.), состоит из трех частей и, по сути, представляет собой катехизис, предназначенный для католического духовенства.

Следует заметить, что несмотря на то, что «Compendium catholicae veritatis» был предназначен в первую очередь для японских учащихся, его сложно отнести к категории полностью адаптированных для японского читателя христианских вероучительных текстов. Безусловно, это связано не только с тем, что текст был написан европейцем, но и с тем, что он распространялся и использовался только в социальных структурах, полностью контролируемых европейцами (в данном случае - учебных заведениях иезуитов). Тем не менее, «Compendium» оказал большое влияние на мировоззрение японских христиан, и, как следствие, на работы, написанные в период официального запрета христианства.

Все учебные заведения иезуитов окончательно прекратили свою деятельность в Японии в связи с принятием «Указа о депортации священников» в 1614 г. Многие преподаватели и учащиеся переехали в Макао, где не было антихристианских гонений. Другие, под риском наказания, рассеялись по Японии и скрывались. Немногие школы всё же продолжали свою образовательную деятельность, но исчезли достаточно быстро. Значительное число выпускников и учащихся учебных заведений иезуитов было убито под пытками за отказ от отречения. Некоторые стали отступниками или даже гонителями христианской веры.

\section{Заключение}

Таким образом, развитие иезуитского образования в Японии стало возможным благодаря множественной поддержке: миссионеров с Запада, которые принесли новую педагогику; даймё, которые приняли иезуитских миссионеров и поддержали их идеи; и, наконец, людей, которые хотели и могли учиться. Учебные заведения Общества Иисуса сумели адаптироваться к незнакомым для европейцев японским культурным условиям. Важнейшим, основополагающим принципом всех учебных заведений иезуитов являлось желание воспитать человека так, чтобы он смог постичь христианскую истину. Многие из тех учащихся, которые смогли довести до конца этот долгий процесс становления, стали священниками или братьями-иезуитами. В большинстве своём они были широко образованными людьми, владеющими несколькими языками и умеющими жить в условиях двух религиозных культур. 
В современной Японии существует множество католических учебных заведений. Большинство из них позиционирует себя как светские образовательные организации, но не скрывает исторической связи с первыми миссионерами и их учебными заведениями. К примеру, официальный сайт одного из самых престижных ВУЗов Японии - Университета Софии (上智大学) содержит информацию о том, что в 1549 г., в своих письмах, Ф. Ксавье выражал надежду построить университет в Японии и его надежды оправдались с основанием Университета Софии. Можно сказать, что благодаря популярности католических учебных заведений в современной Японии, Католическая церковь некоторым образом оказывает влияние на членов японского общества. Однако, в отличие от учебных заведений, созданных иезуитами в XVI и XVII вв., это влияние, очевидно, в большей степени имеет светское значение, а его религиозный характер не всегда очевиден.

Так, иезуитам удалось создать новую для традиционной Японии, альтернативную систему образования. Эти христианские школы сыграли важную роль в распространении новых идей для японской культуры, идей, которые пережили эти образовательные учреждения.

\section{Литература}

1. Новакова О.В., Симонова-Гудзенко Е.К., Ульянов М.Ю. Роль первых европейских ученых и христианских миссионеров в развитии современных знаний в странах Восточной и Юго-Восточной Азии на примере Индонезии, Японии и Вьетнама (XVI-XVII вв.) // Гуманитарные исследования в Восточной Сибири и на Дальнем Востоке. № 3. С. 5-20.

2. Bailey G.A. Art on the Jesuit Mission in Asia and Latin America, 1542-1773. Toronto: University of Toronto Press, 1999. 408 p.

3. Cieslik H. Small Encyclopedia of Japanese Christians. Tokyo: Tokyodo Shuppan, 1999. 403 p.

4. Juan Ruiz-de-Medina S.J. Documentos del Japon 1547-1557. Roma: Institutum Historicum, Italia, $862 \mathrm{p}$.

5. Levy E. Propaganda and the Jesuit Baroque. Berkeley: University of California Press, 2004. 353 p.

6. Moell C. J. The constitutions of the Society of Jesus and their complementary norms: a complete English translation of the official Latin texts. St. Louis: The Institute of Jesuit Sources, 1996. 502 p.

7. Moran J.F. The Japanese and the Jesuits: Alessandro Valignano in Sixteenth-Century Japan. London and New York: Routledge, 1993. $252 \mathrm{p}$.

8. Morris J. H. Rethinking the History of
Conversion to Christianity in Japan: 15491644. St Andrews: University of St Andrews, 2018. $427 \mathrm{p}$.

9. Obara S. Jesuit Education in the Kirishitan Period: Francis Xavier's Longing for a College in the Capital. Tokyo: Kirishitan Bunko, 1989. $54 \mathrm{p}$.

10. Ogawa S. Surrender or Subversion? Contextual and Theoretical Analysis of the Paintings by Japan's Hidden Christians, 16401873. Cincinnati: University of Cincinnati, 2010. 96 p.

11. Raneri G. Folding Screens, Cartography, and the Jesuit Mission in Japan, 1580-1614. Manchester: The University of Manchester, 1980. $287 \mathrm{p}$.

12. Schütte J.F. S.J. Valignano's Mission Principles for Japan. St. Louis: Institute of Jesuit Sources, 1980. 380 p.

13. Taida I. The earliest history of European language education in Japan: Focusing on Latin education by Jesuit missionaries. Classical Receptions Journal, 2014, No. 9, P. 566-586.

14. White M. The Japanese Educational Challenge: A Commitment to Children.

Tokyo: Kodansha International, 1987.210 p.

15. 五野井隆史. キリシタンの文化. 東京: 吉川 弘文館, 2012. 309頁 $=$ Гонои T. Христианская культура. Токио: Ёсикава Кобункан, 2012. 309 с. 
16. 川原一馬. 庭訓往来. 横浜: 坂本龍 馬文庫, 1984. 375頁 = Кадзума К. «Тэйкинорай». Иокогама: Сакамото Рё:ма Бунко, 1984. 375 c.

17. 村上直次郎, 柳谷武夫. イエズス会 士日本通信. 東京: 遊勝堂, 1969. 426頁 $=$ Мураками Н., Янагия Т. Общество Иисуса (Японские Отчеты). Токио: Юсёдо, 1969. $426 \mathrm{c}$.
18. 海老沢有道. エヴオラ屏風文書の研 究. 東京: ナツメ社, 1963, 205頁 = Эбисава А. Исследования документов Эворы. Токио: Натсумэся, 1963. 205 с.

19. 海老沢有道. 南蛮学統の研究 : 近代 日本文化の系譜. 東京: 創文社, 1968. 512頁 = Эбисава А. Изучение школы южных варваров - генеалогия современной японской культуры. Токио: Сёбунся, 1958. 512 с.

\section{Pavel G. NELYUBIN,}

Postgraduate student of the Department of World History and International Relations, Altai State University (Barnaul, Russia).

E-mail: new-wirgil@yandex.ru

\section{Western Education in Traditional Japan: Lessons of Jesuits}

UDC $272 / 273$

Christianity in Japan, Jesuits,

Society of Jesus,

Jesuit pedagogy,

missionaries in Japan, education in traditional Japan

\section{DOI https://doi.org/10.24866/2542-1611/2021-3/61-73}

The article provides a brief overview of the education system in Japan, which was in force at the time of the arrival of the first Christian missionaries. A description is given of how local educational institutions have influenced the Japanese literacy rate, as well as the development of science and art. The motives that prompted the Jesuits to establish their educational institutions in Japan are analyzed. The history of the development of Christian education in Japan from the second half of the 16th to the beginning of the 17th centuries is traced, and the characteristics of the Jesuit pedagogy in the context of Japanese culture are also considered. In addition, the article discusses the Japanese peculiarity of the adoption and adaptation of aspects of foreign culture, especially in those matters relating to education. In particular, the article tells about the history of Western education in traditional Japan. In addition, through the analysis of educational literature and correspondence, educational essays of the Jesuits, the features of the educational activities of the Society of Jesus in traditional Japan are clarified, and an approximate social portrait of students and teachers at educational institutions of the Jesuit Mission is created.

For citation: Nelyubin P. G. Western Education in Traditional Japan: Lessons of Jesuits // Oriental Institute Journal. 2021. № 3. P. 61-73. DOI https://doi.org/10.24866/2542-1611/2021-3/61-73 


\section{References}

1. Novakova

O.V.,

Simonova-

Gudzenko E.K., Ul'yanov M.YU. Rol' pervykh evropejskikh uchenykh i khristianskikh missionerov $\mathrm{v}$ razvitii sovremennykh znanij v stranakh Vostochnoj i YUgo-Vostochnoj Azii na primere Indonezii, YAponii i V'etnama (XVI-XVII vv.) // Gumanitarnye issledovaniya v Vostochnoj Sibiri i na Dal'nem Vostoke. № 3. S. 5-20.

2. Bailey G.A. Art on the Jesuit Mission in Asia and Latin America, 1542-1773. Toronto: University of Toronto Press, 1999. 408 p.

3. Cieslik H. Small Encyclopedia of Japanese Christians. Tokyo: Tokyodo Shuppan, 1999. $403 \mathrm{p}$.

4. Juan Ruiz-de-Medina S.J. Documentos del Japon 1547-1557. Roma: Institutum Historicum, Italia, $862 \mathrm{p}$.

5. Levy E. Propaganda and the Jesuit Baroque. Berkeley: University of California Press, 2004. 353 p.

6. Moell C. J. The constitutions of the Society of Jesus and their complementary norms: a complete English translation of the official Latin texts. St. Louis: The Institute of Jesuit Sources, 1996. 502 p.

7. Moran J.F. The Japanese and the Jesuits: Alessandro Valignano in Sixteenth-Century Japan. London and New York: Routledge, 1993. $252 \mathrm{p}$.

8. Morris J. H. Rethinking the History of Conversion to Christianity in Japan: 15491644. St Andrews: University of St Andrews, 2018. $427 \mathrm{p}$.

9. Obara S. Jesuit Education in the Kirishitan Period: Francis Xavier's Longing for a College in the Capital. Tokyo: Kirishitan Bunko, 1989. $54 \mathrm{p}$.

10. Ogawa S. Surrender or Subversion? Contextual and Theoretical Analysis of the Paintings by Japan's Hidden Christians, 1640-
1873. Cincinnati: University of Cincinnati, 2010. $96 \mathrm{p}$.

11. Raneri G. Folding Screens, Cartography, and the Jesuit Mission in Japan, 1580-1614. Manchester: The University of Manchester, 1980. 287 p.

12. Schütte J.F. S.J. Valignano's Mission Principles for Japan. St. Louis: Institute of Jesuit Sources, 1980. 380 p.

13. Taida I. The earliest history of European language education in Japan: Focusing on Latin education by Jesuit missionaries. Classical Receptions Journal, 2014, No. 9, P. 566-586.

14. White M. The Japanese Educational Challenge: A Commitment to Children. Tokyo: Kodansha International, 1987. 210 p.

15. 五野井隆史. キリシタンの文化. 東京: 吉川 弘文館, 2012. 309頁 = Gonoi T. KHristianskaya kul'tura. Tokio: YOsikava Kobunkan, 2012.309 s.

16. 川原一馬. 庭訓往来. 横浜: 坂本 龍馬文庫，1984. 375頁 = Kadzuma K. «Tehjkinoraj». Iokogama: Sakamoto Ryo:ma Bunko, 1984. $375 \mathrm{~s}$.

17. 村上直次郎，柳谷武夫. イエズス会 士日本通信. 東京: 遊勝堂, 1969. 426頁 $=$ Murakami N., YAnagiya T. Obshhestvo Iisusa (YAponskie Otchety). Tokio: YUsyodo, 1969. $426 \mathrm{~s}$.

18. 海老沢有道. エヴオラ屏風文書の研 究. 東京: ナツメ社, 1963, 205頁 = EHbisava A. Issledovaniya dokumentov EHvory. Tokio: Natsumehsya, 1963. $205 \mathrm{~s}$.

19. 海老沢有道. 南蛮学統の研究 : 近代 日本文化の系譜. 東京: 創文社，1968. 512 頁 = EHbisava A. Izuchenie shkoly yuzhnykh varvarov - genealogiya sovremennoj yaponskoj kul'tury. Tokio: Syobunsya, 1958. $512 \mathrm{~s}$. 